\title{
QUALIDADE FISIOLÓGICA DA SEMENTE E ADUBAÇÃO COM ZINCO NA CULTURA DO MILHO-DOCE
}

\author{
Lilian Faria de Melo $^{1}$, Stella Tosta Leal $^{2}$, Simone Aparecida de Oliveira ${ }^{3}$, Marcelo Fagioli ${ }^{4}$, \\ Marco Eustáquio de Sá ${ }^{5}$ \\ ${ }^{1}$ Doutoranda do Programa de Pós Graduação em Agronomia da UNESP - Campus Jaboticabal (SP). \\ ${ }^{2}$ Doutoranda do Programa de Pós Graduação em Agronomia da UNESP - Campus Ilha Solteira (SP). \\ ${ }^{3}$ Doutora em Agronomia e Assistente de Suporte Acadêmico II da UNESP - Campus Ilha Solteira (SP). \\ ${ }^{4}$ Docente da UnB - Universidade de Brasília (DF). \\ ${ }^{5}$ Docente da UNESP - Campus de Ilha Solteira (SP).
}

RESUMO: O Brasil como um grande produtor de milho comum, apresenta grande potencial para produção de milho-doce, que é muito cultivado na América do Norte, e aqui fica restrito devido ao pouco conhecimento por parte dos consumidores e da baixa disponibilidade de sementes. $\mathrm{O}$ objetivo deste trabalho foi verificar se o vigor de sementes e adução com zinco interferem nos componentes de produção e no estado nutricional de três híbridos de milho-doce. Foram utilizadas sementes de três híbridos de milho-doce, classificados quanto aos níveis de vigor, em alto, médio e baixo vigor. Foram testadas seis doses de zinco, utilizando como fonte o sulfato de zinco $\left(\mathrm{ZnSO}_{4} \cdot 7 \mathrm{H}_{2} \mathrm{O}\right),(0,2,4,6,8$ e 10 $\mathrm{kg}$ de $\mathrm{Zn} \mathrm{ha}{ }^{-1}$ ), aplicadas na semeadura, juntamente com a adubação de NPK recomendada para a cultura. Concluiu-se que os três híbridos de milho-doce se apresentaram aptos para serem cultivados na região de Selvíria-MS. Há diferença de comportamento entre os híbridos em relação à produção comercial de espigas, sendo os híbridos $\mathrm{B}$ e $\mathrm{C}$ superiores ao híbrido A. Sementes de lotes de alto vigor proporcionaram maior desenvolvimento inicial de plantas, maior número de grãos por fileira e maior produtividade comercial de espigas de milho-doce. A adubação com zinco não alterou as características agronômicas e a produtividade dos híbridos de milho-doce.

Palavras-chave: Zea mays L. Vigor de sementes. Nutrição mineral.

\section{PHYSIOLOGICAL QUALITY OF THE SEEDS AND FERTILIZATION WITH ZINC ON CORN SWEET CROP}

\begin{abstract}
Brazil as a great producer of corn presents a high potential for the production of sweet corn, which is very grown in North America, and here it keeps restricted due to the low level of knowledge for the consumers and the low availability of seeds. The objective of this study was to determine whether the seed vigour and zinc fertilization interfere in the production components and nutritional status of three sweet corn hybrids. In order to research, we used sweet corn seeds, classified according to the levels of vigour: more vigorous, intermediate level of vigour and less vigorous. Six doses of zinc were tested, by using zinc sulfate as a source $\left(\mathrm{ZnSO}_{4} \cdot 7 \mathrm{H}_{2} \mathrm{O}\right): 0,2,4,6,8$ e $10 \mathrm{~kg}$ de $\mathrm{Zn} \mathrm{ha}^{-1}$, applied at sowing, along with the fertilization of NPK recommended for the crop. It was concluded
\end{abstract}

Cultura Agronômica, Ilha Solteira, v.24, n.3, p.289-308, 2015 
that three sweet corn hybrids performed able to be cultivated in the region of Selvíria-MS. There is a difference in behavior among hybrids for commercial production of spikes, and the hybrids B and C were better than hybrid A. Seeds from the high level vigour lot provided a higher number of grains per row and higher commercial productivity of sweet corn spikes. The fertilization by zinc didn't alter the agronomical characteristics and the productivity of the sweet corn hybrids which were tested.

Key words: Zea mays L. Vigour of seeds. Mineral nutrition.

\section{INTRODUÇÃO}

O milho doce (Zea mays L.) destina-se exclusivamente ao consumo humano. Sua utilização é bastante diversificada, podendo ser consumido em conserva (enlatado), congelado na forma de espigas ou grãos, desidratado, ou consumido "in natura" (PEREIRA FILHO; CRUZ, 2002; ARAGÃO, 2002; BORIN, 2005; OLIVEIRA JUNIOR et al., 2006).

No Brasil, sua produção é voltada para o processamento industrial, sendo ainda pouco difundido para o consumo "in natura" pelo restrito número de cultivares adaptados ao clima tropical (BARBIERI et al., 2005). A produção concentra-se nos estados do Rio Grande do Sul, São Paulo, Minas Gerais, Goiás, Distrito Federal e Pernambuco (PARENTONI et al., 1990).

A diferença básica entre o milho doce e os outros tipos de milho se deve à presença de alelos mutantes que bloqueiam a conversão de açúcares em amido, no endosperma, conferindo o caráter doce, tornando o milho doce enrugado e translúcido quando seco, desencadeando mudanças na sua qualidade, no aspecto da planta e na viabilidade das sementes (GAMA et al., 1983). Na fase de grãos leitosos, seus grãos são tenros e possuem maior quantidade de sacarose, dextrinas e vitaminas, em relação ao milho verde comum (STORK; LOVATO, 1991).

Várias pesquisas realizadas com o milho doce têm demonstrado qualidade inferior de suas sementes quando comparadas com o milho verde comum, possivelmente devido à maior sensibilidade e suscetibilidade aos danos físicos e àqueles decorrentes das alterações bioquímicas. Waters Júnior e Blanchette (1983) afirmaram que a menor porcentagem de emergência das plântulas no milho doce ocorre em função do manuseio incorreto das sementes e, ainda, de outros fatores que causam a redução da sua qualidade. Dessa forma, a semente é considerada a principal responsável pela produção agrícola e sua qualidade afeta diretamente todo o desenvolvimento da cultura, desde a emergência de plântulas até a colheita.

O vigor das sementes é um dos principais atributos da qualidade fisiológica a ser considerado na implantação de uma lavoura. Para Tekrony e Egli (1991), o uso de sementes de alto vigor é justificado em todas as culturas, para assegurar adequada população de plantas sobre uma ampla variação de condições ambientais de campo encontradas durante a emergência, e possibilitar aumento na produção.

Cultura Agronômica, Ilha Solteira, v.24, n.3, p.289-308, 2015 
Sementes com baixo vigor podem provocar reduções na velocidade de emergência, na uniformidade, na emergência total, no tamanho inicial e no estabelecimento de estandes adequados (HÖFS, 2003; MACHADO, 2002; VANZOLINI; CARVALHO, 2002; SCHUCH et al., 1999; SCHUCH; LIN, 1982), fatores esses que podem influenciar a acumulação de matéria seca, e assim afetar o rendimento (KOLCHINSKI et al., 2005).

Considerando que sementes com baixo vigor poderão apresentar plântulas menos desenvolvidas, sistemas radiculares com menor dimensão, maior tempo de desenvolvimento e menor resistência a condições adversas, tem-se que estes fatores poderão limitar o potencial de absorção de nutrientes pelas plantas, principalmente se levar em consideração aspectos ligados a absorção como, fluxo de massa, interceptação radicular e difusão.

Dentre os problemas de baixa produtividade das culturas encontram-se as deficiências nutricionais, onde a sua presença em solos anteriormente sob vegetação de cerrado são mais evidentes. $\mathrm{O}$ zinco se encontra entre os nutrientes em que na maioria dos casos de deficiência nas plantas o mesmo é relatado, sendo de grande importância, como ativador enzimático, granação das sementes e diminuição do chochamento, principalmente em gramíneas. Assim uma adequada adubação com zinco, principalmente por que muitas formulações são deficientes desse nutriente são de vital importância para a obtenção de níveis adequados de produtividade.

O micronutriente Zinco é considerado elemento de grande importância na nutrição do milho, pois participa como componente de um grande número de enzimas, sendo que suas funções básicas na planta estão relacionadas ao metabolismo de carboidratos, proteínas e fosfatos, e na formação de estruturas das auxinas, RNA e ribossomos. Desta forma, mesmo exigido em pequenas quantidades, o $\mathrm{Zn}$ é fundamental e a falta ou excesso deste nutriente pode causar desequilíbrio nutricional à planta de milho, afetando a produtividade das mesmas (PRADO et al., 2007).

Diante do exposto este trabalho teve como objetivo verificar se o vigor de sementes e adução com zinco interferem nos componentes de produção e no estado nutricional de três híbridos de milho-doce.

\section{MATERIAL E MÉTODOS}

O experimento foi conduzido no ano agrícola de 2011/12, na área experimental da Fazenda de Ensino e Pesquisa, pertencente à Faculdade de Engenharia - Campus de Ilha Solteira - UNESP, localizada no município de Selvíria-MS, cujas coordenadas geográficas são $51^{\circ} 22^{\prime}$ de longitude Oeste e $20^{\circ} 22^{\prime}$ de latitude Sul, com altitude de 335 metros. O solo da área experimental foi classificado segundo DEMATTÊ (1980) e reclassificado segundo o Sistema Brasileiro de Classificação de Solos (EMBRAPA, 2006), como um LATOSSOLO VERMELHO Distrófico. O clima é do tipo Aw (Clima tropical, com inverno seco), segundo a classificação de Köeppen, apresentando temperatura média anual de $24,5^{\circ} \mathrm{C}$, precipitação pluvial anual de 1.232,2 mm e uma umidade relativa média de 64,8\% (HERNANDEZ et al., 1995).

Cultura Agronômica, Ilha Solteira, v.24, n.3, p.289-308, 2015 
A distribuição de precipitação pluvial bem como a temperatura média durante a condução do experimento esta apresentada na Figura 1. A cultura foi irrigada de acordo com as exigências hídricas da cultura com sistema de irrigação do tipo canhão autopropelido.

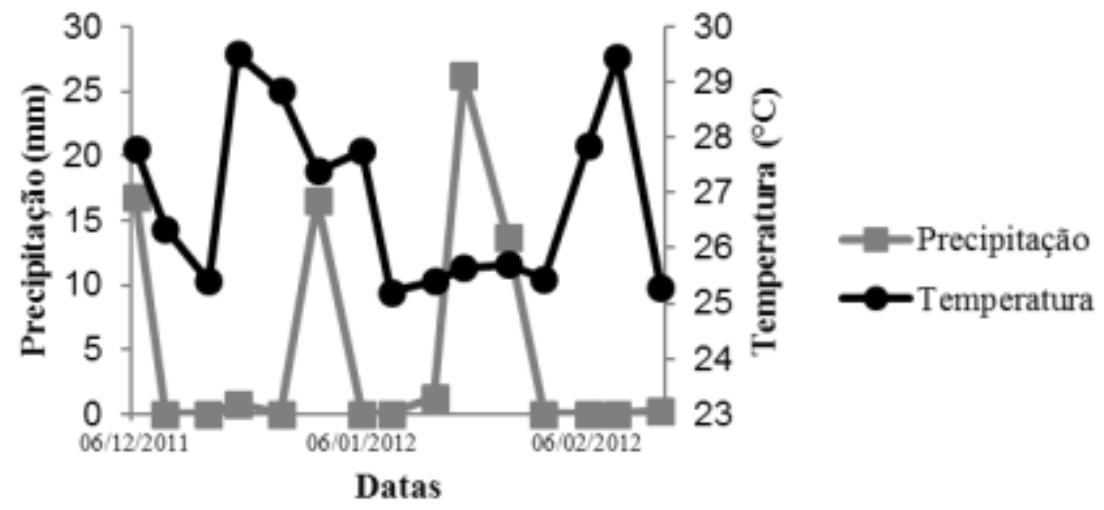

Figura 1. Médias de temperatura máxima e mínima e precipitação, no período de desenvolvimento do experimento em campo, no município de Selvíria - MS.

Para a realização da pesquisa, foram utilizadas sementes de três híbridos de milhodoce apresentando três níveis de vigor. Os híbridos foram denominados como A, B e C. Para a caracterização dos níveis de vigor, as sementes foram envelhecidas artificialmente. Assim, sementes sem envelhecimento foram consideradas como amostras de alto nível de vigor, enquanto que as amostras de médio e baixo vigor foram obtidas pelo envelhecimento das sementes por 48 e 72 horas a $41{ }^{\circ} \mathrm{C}$, respectivamente. As sementes foram armazenadas em câmara fria e seca a $15{ }^{\circ} \mathrm{C}$ e $40 \%$ de UR até o início das análises experimentais.

Para caracterizar a qualidade inicial das sementes utilizadas na semeadura, foram realizados os seguintes testes:

Teor de água - Foi determinado utilizando o método da estufa a $105 \pm 3^{\circ} \mathrm{C}$ por 24 horas, antes e após o envelhecimento acelerado (BRASIL, 2009).

Teste de germinação - foi conduzido com quatro repetições de 50 sementes por lote, em rolos de papel-toalha. A quantidade de água adicionada foi equivalente a 2,5 vezes a massa do substrato seco. Os rolos foram acondicionados em germinador e mantidos à temperatura de $25 \pm 1^{\circ} \mathrm{C}$, com as contagens realizadas no quarto e sétimo dias após a instalação do teste, conforme os critérios estabelecidos pelas Regras para Análise de Sementes (BRASIL, 2009), contabilizando-se a porcentagem de plântulas normais.

Primeira contagem de germinação (PC) - foi realizada em conjunto com o teste de germinação, computando-se as porcentagens de plântulas normais verificadas no quarto dia após a semeadura.

Dano mecânico (DM) - foi realizado utilizando duas subamostras de 100 sementes. Cada subamostra foi colocada em uma placa de Petri e submersa em amaranto a 0,5\% por aproximadamente cinco minutos. Em seguida, foi eliminado o excesso de solução de amaranto e cada subamostra foi distribuída sobre folhas de papel toalha, procedendo-se a contagem do número de sementes danificadas. Os resultados foram expressos em 
porcentagem média de sementes danificadas por subamostra.

Teste de envelhecimento acelerado (EA) - Foi conduzido com quatro subamostras de 50 sementes para cada tratamento, descrito por Marcos Filho (1994), onde as sementes foram distribuídas em camada única sobre a tela de inox e colocadas em caixas plásticas (Gerbox), contendo $40 \mathrm{~mL}$ de água destilada no fundo e após colocação da tampa, as caixas foram levadas ao germinador regulado à temperatura de $41^{\circ} \mathrm{C}$ onde permaneceram por 72 horas. Decorrido este período, as sementes foram semeadas conforme descrito para o teste de germinação, com a avaliação das plântulas normais sendo realizada no quarto dia após a instalação do teste.

Teste de condutividade elétrica (CE) - foi realizado utilizando quatro subamostras de 25 sementes em metodologia semelhante à recomendada por Loeffler et al. (1988), Vieira (1994); Hampton e Tekrony (1995) para 50 sementes. Cada subamostra foi pesada em balança de precisão $(0,001 \mathrm{~g})$, usando pelo menos duas casa decimais, e colocadas para embeber em um recipiente contendo $75 \mathrm{~mL}$ de água deionizada e mantidas em um germinador regulado à temperatura de $25^{\circ} \mathrm{C}$ durante 24 horas (LOEFFLER et al., 1988). Após a embebição das sementes foi realizada a leitura da condutividade elétrica da solução de embebição, com condutivímetro, com sensor aferido com constante de eletrodo 1,0. O resultado obtido no condutivímetro foi dividido pela massa de cada subamostra, de modo que o resultado final foi expresso em $\mu \mathrm{mho} . \mathrm{cm}^{-1} \cdot \mathrm{g}^{-1}$.

Tabela 1. Características químicas do solo da área experimental nas camadas 0-10 e 10-20 $\mathrm{cm}$ de profundidade.

\begin{tabular}{lcc}
\hline \multicolumn{1}{c}{ Características } & \multicolumn{2}{c}{ Amostra coletada } \\
\cline { 2 - 3 } & $\mathbf{0 - 1 0} \mathbf{~ c m}$ & $\mathbf{1 0 - 2 0} \mathbf{~ c m}$ \\
\hline $\mathrm{pH}\left(\mathrm{CaCl}_{2}\right)$ & 5,0 & 4,8 \\
$\mathrm{MO}\left(\mathrm{g} / \mathrm{dm}^{3}\right)$ & 18,0 & 17,0 \\
$\mathrm{P}-\mathrm{resina}\left(\mathrm{mg} / \mathrm{dm}^{3}\right)$ & 19,0 & 11,0 \\
$\mathrm{~K}\left(\mathrm{mmol}_{\mathrm{c}} / \mathrm{dm}^{3}\right)$ & 3,7 & 2,1 \\
$\mathrm{Ca}\left(\mathrm{mmol}_{\mathrm{c}} / \mathrm{dm}^{3}\right)$ & 13,0 & 11,0 \\
$\mathrm{Mg}\left(\mathrm{mmol}_{\mathrm{c}} / \mathrm{dm}^{3}\right)$ & 9,0 & 8,0 \\
$\mathrm{H}+\mathrm{Al}\left(\mathrm{mmol}_{\mathrm{c}} / \mathrm{dm}^{3}\right)$ & 34,0 & 33,0 \\
$\mathrm{SB}\left(\mathrm{mmol}_{\mathrm{c}} / \mathrm{dm}^{3}\right)$ & 25,7 & 21,1 \\
$\mathrm{Al}\left(\mathrm{mmol} / \mathrm{dm}^{3}\right)$ & 1,0 & 2,0 \\
$\mathrm{CTC}\left(\mathrm{mmol}_{\mathrm{c}} / \mathrm{dm}^{3}\right)$ & 59,7 & 54,1 \\
$\mathrm{~V}(\%)$ & 43,0 & 39,0 \\
$\mathrm{~B}\left(\mathrm{mg} / \mathrm{dm}^{3}\right)$ & 0,2 & 0,2 \\
$\mathrm{Cu}\left(\mathrm{mg} / \mathrm{dm}^{3}\right)$ & 3,9 & 3,7 \\
$\mathrm{Fe}\left(\mathrm{mg} / \mathrm{dm}^{3}\right)$ & 11,0 & 11,0 \\
$\mathrm{Mn}\left(\mathrm{mg} / \mathrm{dm}^{3}\right)$ & 34,3 & 29,3 \\
$\mathrm{Zn}\left(\mathrm{mg} / \mathrm{dm}^{3}\right)$ & 0,4 & 0,4 \\
$\mathrm{~m}(\%)$ & 4,0 & 9,0 \\
$\mathrm{~S}\left(\mathrm{mg} / \mathrm{dm}^{3}\right)$ & 14,0 & 16,0 \\
\hline
\end{tabular}

Antes da instalação do experimento foram coletadas amostras de solo da área experimental de acordo com a metodologia proposta por Raij e Quaggio (1983). Foram

Cultura Agronômica, Ilha Solteira, v.24, n.3, p.289-308, 2015 
coletadas amostras simples de 0-10 e 10-20 cm de profundidade e analisadas no Laboratório de Fertilidade do Solo da Universidade Estadual Paulista - UNESP (Tabela 1).

Como se observa, o solo do local apresenta abaixo da faixa considerada adequada para teor de zinco no solo $\left(0,40 \mathrm{mg} / \mathrm{dm}^{3}\right)$, sendo o teor médio entre 0,60 a $1,20 \mathrm{mg} / \mathrm{dm}^{3}$ (RAIJ et al., 1997) pelo método do DTPA, o que poderia ser fator limitante para a obtenção de altas produtividades.

O delineamento experimental utilizado foi em blocos casualizados, em esquema fatorial 3x3x6 com 54 tratamentos e 4 repetições. Os tratamentos foram constituídos pela combinação de três híbridos (A, B e C), três níveis de vigor (baixo, médio e alto vigor) e seis doses de zinco $\left(0,2,4,6,8\right.$ e $\left.10 \mathrm{~kg} \mathrm{ha}^{-1}\right)$ aplicado via solo, utilizando como fonte o sulfato de zinco $\left(\mathrm{ZnSO}_{4}\right)$.

As parcelas foram constituídas por quatro linhas de $4 \mathrm{~m}$ de comprimento. Como área útil foi considerada as duas fileiras centrais, eliminando-se as duas das extremidades, sendo a área útil de $6,0 \mathrm{~m}^{2}$.

O preparo da área constituiu de uma aração, com arado de aiveca e duas gradagens, sendo uma normal e uma niveladora. A semeadura foi realizada manualmente no dia 06 de dezembro de 2011, à profundidade aproximada de cinco centímetros, com cinco sementes por metro espaçadas de 0,20 m e com espaçamento de 0,75 m entre linhas. Aos 28 dias após a semeadura foi realizado o desbaste, ajustando o estande para cada híbrido, com estande médio de 65 mil plantas ha ${ }^{-1}$. A adubação foi realizada juntamente como a semeadura e constou da aplicação de $400 \mathrm{~kg} \mathrm{ha}^{-1}$ da fórmula 05-25-15. Foram realizadas duas adubações de cobertura, a primeira no estádio vegetativo $\mathrm{V} 4$, com $40 \mathrm{~kg} \mathrm{ha}^{-1}$ de $\mathrm{N}$ e $\mathrm{K}_{2} \mathrm{O}$ da formulação 20-00-20, e a segunda no estádio V6 com $45 \mathrm{~kg} \mathrm{ha}^{-1}$ de N, usando como fonte a uréia. Os tratos culturais foram efetuados conforme a necessidade e recomendação da cultura.

As sementes foram tratadas com os fungicidas Fludioxinil e Metalaxyl-M (3,75 g i.a./100 kg sementes), Carboxin e Thiram (188 g i.a./100 kg sementes), e Captan (120 g i.a./100 kg sementes) para controle preventivo dos fungos Pythium aphanidermatum; Penicillium sp., Pephalosporium sp. e Aspergillus sp. e Fusarium moliniforme, respectivamente. $\mathrm{O}$ controle de plantas daninhas foi realizado em pré-emergência com a aplicação de $1665 \mathrm{~g} \mathrm{ha}^{-1}$ de metolachlor $+2305 \mathrm{~g} \mathrm{ha}^{-1}$ de atrazina. $\mathrm{O}$ controle de lagartas do cartucho foi realizado com uma aplicação de $129 \mathrm{~g} \mathrm{ha}^{-1}$ de metomil $+48 \mathrm{~g} \mathrm{ha}^{-1} \mathrm{de}$ triflumuron.

O controle de plantas daninhas foi realizado em pré-emergência com a aplicação de $1665 \mathrm{~g} \mathrm{ha}^{-1}$ de metolachlor $+2305 \mathrm{~g} \mathrm{ha}^{-1}$ de atrazina. O controle de lagartas do cartucho foi realizado com uma aplicação de $129 \mathrm{~g} \mathrm{ha}^{-1}$ de metomil $+48 \mathrm{~g} \mathrm{ha}^{-1}$ de triflumuron.

A colheita das espigas para consumo "in natura" foi realizada 74 dias após a semeadura, no dia 18 de fevereiro de 2012, quando os grãos apresentavam entre 60 e $70 \%$ de umidade, colhendo-se todas as espigas da área útil manualmente. A umidade dos grãos foi determinada utilizando-se o método de estufa a $105 \pm 3^{\circ} \mathrm{C}$ por 24 horas (BRASIL, 2009). 
Depois de colhidas, foram separadas 10 espigas de cada parcela, para avaliações das características agronômicas.

Características avaliadas:

- Teor foliar de nutrientes: obtido do conjunto de 10 folhas coletadas da base da espiga de cada parcela por ocasião do pendoamento, utilizando-se o terço central da folha, segundo o método descrito por Cantarella et al. (1997). O material foi seco e moído e depois levados ao laboratório para determinação dos teores de N, P, K, Ca, Mg, S e Zn).

- Número total de espigas: obtido pela contagem de todas as espigas colhidas, na área útil da parcela. Os dados de número de espigas foram transformados para número de espigas por hectare.

- Número de espigas comerciais: obtido pela contagem de todas as espigas despalhadas que apresentarem diâmetro variando de 3 a $6 \mathrm{~cm}$, e comprimento de 14 a 20 $\mathrm{cm}$. Os dados referentes ao número de espigas comerciais foram transformados para número de espigas por hectare.

- Produtividade total de espigas com palha: obtido pela pesagem de todas as espigas colhidas na área útil da parcela, em balança digital. Os dados transformados para quilogramas por hectare.

- Produtividade total de espigas sem palha: obtido pela pesagem de todas as espigas colhidas na área útil da parcela, em balança digital. Os dados transformados para quilogramas por hectare.

- Produtividade de espigas comerciais sem palha: obtido pela pesagem em balança digital de todas as espigas comercias, que apresentaram diâmetro variando de 3 a $6 \mathrm{~cm}$, e comprimento de 14 a $20 \mathrm{~cm}$, que não apresentavam defeitos como mau enchimento de grãos e defeitos causados por pragas e/ou doenças, principalmente. Os dados de massa de espigas comerciais foram transformados para quilograma por hectare.

- Índice de produtividade comercial: relação entre produtividade de espigas comerciais sem palha e produtividade total de espigas sem palha. Os dados foram apresentados em porcentagem.

- Comprimento da espiga: comprimento médio de dez espigas por parcela, medidos em centímetros, com o auxílio de uma régua graduada.

- Diâmetro da espiga: diâmetro médio de dez espigas comerciais de cada parcela, medidos em milímetros, a partir de três centímetros da base da espiga.

- Número de grãos por fileira: obtido pela contagem de todos os grãos de cinco fileiras consecutivas das 10 espigas por parcela. Foi realizada uma média para a apresentação dos dados.

- Número de fileiras de grãos por espiga: obtido pela contagem de todas as fileiras das 10 espigas coletadas na área útil do experimento. Foi realizada uma média para a apresentação dos dados.

Cultura Agronômica, Ilha Solteira, v.24, n.3, p.289-308, 2015 
- Número de grãos por espiga: obtido pela multiplicação dos dados do número de fileiras pelo número de grãos por fileira das 10 espigas coletadas na área útil do experimento. Foi realizada uma média para a apresentação dos dados.

$\mathrm{Na}$ análise estatística foi utilizado o programa Sisvar (FERREIRA, 2000), com as médias comparadas pelo teste de Tukey a 5\% de probabilidade. Nas análises dos efeitos de doses de Zinco foram ajustadas regressões polinomiais.

\section{RESULTADOS E DISCUSSÃO}

A caracterização inicial dos híbridos e seus respectivos lotes de sementes (Tabela 2) demonstraram haver diferenças em termos de porcentagem de germinação entre os híbridos e seus lotes, entretanto superiores a $60 \%$, que é considerado o valor mínimo para a comercialização de sementes de milho-doce no Brasil (BRASIL, 2005).

Tabela 2. Caracterização inicial dos híbridos e lotes de sementes. Teor de água (TA, \%); teor de água após o envelhecimento acelerado (TA - após EA, \%); germinação (G, \%); dano mecânico (DM, \%); envelhecimento acelerado (EA, \%); primeira contagem de germinação $(\mathrm{PC}, \%)$ e condutividade elétrica $\left(\mathrm{CE}, \mu \mathrm{mho} \cdot \mathrm{cm}^{-1} \cdot \mathrm{g}^{-1}\right)$.

\begin{tabular}{cccccccc}
\hline Híbridos & TA & TA (após EA) & G & DM & EA & PC & CE \\
\hline A & $16 \mathrm{a}$ & $31 \mathrm{a}$ & $75 \mathrm{c}$ & $20 \mathrm{a}$ & $64 \mathrm{c}$ & $60 \mathrm{c}$ & $99,37 \mathrm{a}$ \\
B & $15 \mathrm{a}$ & $32 \mathrm{a}$ & $83 \mathrm{~b}$ & $17 \mathrm{ab}$ & $70 \mathrm{~b}$ & $69 \mathrm{~b}$ & $31,97 \mathrm{~b}$ \\
$\mathrm{C}$ & $15 \mathrm{a}$ & $31 \mathrm{a}$ & $88 \mathrm{a}$ & $16 \mathrm{~b}$ & $75 \mathrm{a}$ & $79 \mathrm{a}$ & $39,05 \mathrm{~b}$ \\
& & & & & & & \\
\hline Lotes & & & & & & & \\
Alto & $15 \mathrm{~b}$ & $32 \mathrm{a}$ & $90 \mathrm{a}$ & $17 \mathrm{a}$ & $77 \mathrm{a}$ & $72 \mathrm{a}$ & $54,58 \mathrm{a}$ \\
Médio & $15 \mathrm{~b}$ & $31 \mathrm{a}$ & $81 \mathrm{~b}$ & $17 \mathrm{a}$ & $70 \mathrm{~b}$ & $68 \mathrm{a}$ & $66,55 \mathrm{~b}$ \\
Baixo & $18 \mathrm{a}$ & $31 \mathrm{a}$ & $75 \mathrm{c}$ & $18 \mathrm{a}$ & $63 \mathrm{c}$ & $68 \mathrm{a}$ & $69,25 \mathrm{~b}$ \\
\hline CV & 7,56 & 3,31 & 5,08 & 8,98 & 5,62 & 9,19 & 21,99 \\
\hline
\end{tabular}

${ }^{1}$ Médias seguidas pela mesma letra, na coluna, não diferem entre si, em nível de 5\% de probabilidade pelo teste de Tukey. CV: coeficiente de variação.

Com relação aos híbridos (Tabela 2), os valores obtidos para a germinação das sementes, envelhecimento acelerado e primeira contagem de germinação indicaram uma superioridade das sementes do híbrido $\mathrm{C}$ em relação às do híbrido $\mathrm{B}$ e estas em relação às sementes do híbrido A. Para danos mecânicos e condutividade elétrica não foram detectadas diferenças significativas entre as sementes dos dois híbridos $\mathrm{C}$ e $\mathrm{B}$, porém as sementes dos dois híbridos apresentaram qualidade superior às do híbrido A. Estas diferenças observadas podem estar ligadas à adaptação do híbrido às condições edafoclimática de Selvíria-MS por ocasião da pesquisa.

Em relação ao teor de água nas sementes verificou-se que não houve diferença significativa entre os híbridos antes e após o teste de envelhecimento acelerado.

Cultura Agronômica, Ilha Solteira, v.24, n.3, p.289-308, 2015 
Em relação aos lotes, foram observadas diferenças claras de vigor de sementes. Quanto ao teor de água observou-se que os lotes de alto e médio vigor apresentaram teor de água inferior quando comparado com o lote de baixo vigor, não houve diferença significativa para o teste após o envelhecimento acelerado, o que indica que provavelmente as condições de umidade e temperatura impuseram às sementes a mesma intensidade de deterioração.

Com relação à condutividade elétrica (Tabela 2), os aumentos nos valores de condutividade elétrica corresponderam à queda na porcentagem de germinação e vigor das sementes, tanto na comparação entre híbridos com entre os lotes do mesmo híbrido, fato esse semelhante à literatura, em que aumentos nos valores de condutividade elétrica correspondem à maior lixiviação de solutos e, portanto, à diminuição na qualidade fisiológica das sementes (POWELL, 1986; MARCOS FILHO et al., 1990; SÁ, 1999). Os resultados dos lotes corroboram as observações de Loeffler et al. (1988) e Vieira et al. (1998) com soja e Fagioli (1997) com milho, que constataram correlações inversas significativas entre os valores de condutividade elétrica com os de germinação e envelhecimento acelerado. Santos (2004) se referiu à existência de correlação significativa entre condutividade elétrica e germinação. Do mesmo modo, Vieira et al. (2001) verificaram que a baixa qualidade das sementes, obtidas no teste de envelhecimento acelerado, correlacionou-se com mudança na integridade das membranas medida por meio de teste de condutividade elétrica.

Não houve efeito significativo para a interação híbridos e lotes para todas as variáveis testadas.

Para os teores de nutrientes, as diferenças observadas entre os híbridos (Tabela 3) podem ser um indicativo de maior eficiência de determinados materiais em absorver nutrientes. Em relação aos lotes de sementes milho-doce com diferentes níveis de vigor observou-se que a maior concentração $\mathrm{N}, \mathrm{P}$ e $\mathrm{Mg}$ nas folhas de plantas de baixo e médio vigor pode ser um indicativo de um efeito de diluição, tendo-se em vista que as plantas oriundas destas sementes eram menores por ocasião da avaliação da altura de plantas.

Como se verifica (Tabela 3), os teores de nutrientes se apresentam dentro das faixas consideradas adequadas para a cultura do milho (CANTARELLA et al., 1997). Observou-se que houve diferença significativa entre os híbridos e entre os lotes de milho-doce em relação ao teor de nitrogênio. Os híbridos A e B apresentaram valores superiores (34,65 e 33,77 g $\left.\mathrm{kg}^{-1}\right)$ em relação ao híbrido $\mathrm{C}\left(27,61 \mathrm{~g} \mathrm{~kg}^{-1}\right)$. Para os lotes, o lote de menor vigor foi o que apresentou maior concentração de nitrogênio na folha quando comparado com os lotes de alto e médio vigor. Em relação às doses de zinco não houve ajuste às equações testadas.

O teor de fósforo nas folhas (Tabela 3) também apresentou diferença significativa, o híbrido A apresentou concentrações superior aos demais híbridos. Para os lotes observou-se que houve diferença significativa, o lote de médio vigor foi o que apresentou maior concentração de fósforo quando comparados com os lotes de alto e baixo vigor. Em relação às doses de zinco não houve ajuste de regressões. A interação significativa entre híbridos e lotes para teores foliares de fósforo (Tabela 4) demonstraram que os híbridos A e B

Cultura Agronômica, Ilha Solteira, v.24, n.3, p.289-308, 2015 
apresentaram resultados semelhantes entre os lotes, já o híbrido $\mathrm{C}$ apresentou melhores resultados para o lote de médio vigor em relação aos lotes de alto e baixo vigor. Entre os lotes, foi possível observar que para o lote de maior vigor o hibrido A apresentou melhores resultados em relação aos híbridos $\mathrm{B}$ e $\mathrm{C}$, para o lote de vigor intermediário os híbridos não apresentaram diferença significativa, quando se comparou o lote de baixo vigor, observouse que os híbridos A e B foram os que apresentaram melhores resultados quando comparados ao híbrido A.

Tabela 3. Médias dos teores de macro e micronutrientes nas folhas de três híbridos de milho doce, divididos em três lotes (níveis de vigor) submetidos a seis doses de sulfato de zinco.

\begin{tabular}{|c|c|c|c|c|c|c|c|c|}
\hline & $\mathbf{N}$ & $\mathbf{P}$ & $\mathbf{K}$ & $\mathbf{C a}$ & Mg & $\mathbf{S}$ & $\mathbf{Z n}$ \\
\hline & & \multicolumn{6}{|c|}{ g kg $^{-1}$} & $\mathrm{mg} \mathrm{kg}^{-1}$ \\
\hline \multirow{3}{*}{ Híbridos } & A & $34,65 \mathrm{a}$ & $3,27 \mathrm{a}$ & $28,04 \mathrm{a}$ & $4,37 \mathrm{a}$ & $2,06 \mathrm{a}$ & $2,15 \mathrm{a}$ & $23,47 \mathrm{a}$ \\
\hline & B & $33,77 \mathrm{a}$ & $2,96 \mathrm{~b}$ & $29,02 \mathrm{a}$ & $4,50 \mathrm{a}$ & $1,82 \mathrm{~b}$ & $1,76 \mathrm{~b}$ & $25,83 \mathrm{a}$ \\
\hline & $\mathrm{C}$ & $27,61 \mathrm{~b}$ & $2,83 \mathrm{~b}$ & $28,60 \mathrm{a}$ & $4,47 \mathrm{a}$ & $1,57 \mathrm{c}$ & $1,84 \mathrm{~b}$ & $24,02 \mathrm{a}$ \\
\hline \multirow{3}{*}{ Lotes } & Alto & $31,28 \mathrm{~b}$ & $2,91 \mathrm{~b}$ & $28,56 \mathrm{a}$ & $4,33 \mathrm{a}$ & $1,77 \mathrm{~b}$ & $1,97 \mathrm{a}$ & $24,58 \mathrm{a}$ \\
\hline & Médio & $31,83 \mathrm{ab}$ & $3,17 \mathrm{a}$ & $28,08 \mathrm{a}$ & $4,51 \mathrm{a}$ & $1,86 \mathrm{a}$ & $1,90 \mathrm{a}$ & $24,02 \mathrm{a}$ \\
\hline & Baixo & $32,91 \mathrm{a}$ & $2,98 a b$ & $29,02 \mathrm{a}$ & $4,51 \mathrm{a}$ & $1,82 \mathrm{ab}$ & $1,87 \mathrm{a}$ & $24,72 \mathrm{a}$ \\
\hline \multirow{6}{*}{$\begin{array}{c}\text { Doses de } \\
\text { zinco } \\
\left(\mathrm{Kg} \mathrm{ha}^{-1}\right)\end{array}$} & 0 & 31,14 & 3,18 & 29,16 & 4,40 & 1,88 & 2,02 & $20,55^{1}$ \\
\hline & 2 & 31,65 & 3,06 & 28,62 & 4,47 & 1,87 & 1,97 & 22,50 \\
\hline & 4 & 31,92 & 2,97 & 28,82 & 4,36 & 1,75 & 1,86 & 23,05 \\
\hline & 6 & 32,09 & 3,05 & 28,08 & 4,56 & 1,83 & 1,81 & 26,11 \\
\hline & 8 & 32,48 & 2,86 & 28,66 & 4,53 & 1,84 & 1,89 & 24,72 \\
\hline & 10 & 32,78 & 3,00 & 28,00 & 4,36 & 1,74 & 1,93 & 29,72 \\
\hline
\end{tabular}

\begin{tabular}{cccccccc}
\hline Teste F & \multicolumn{7}{c}{ F } \\
Híbrido (H) & $0,0001^{* *}$ & $0,0001^{* *}$ & 0,3785 & 0,2831 & $0,0001^{* *}$ & $0,0001^{* *}$ & 0,0620 \\
Lotes (L) & $0,0319^{*}$ & $0,0067 * *$ & 0,4129 & 0,0607 & $0,0537 *$ & 0,3364 & 0,7786 \\
Doses (D) & 0,4970 & 0,1301 & 0,8403 & 0,4276 & 0,0570 & 0,2917 & $0,0001 * *$ \\
H x L & 0,3913 & $0,0005^{* *}$ & 0,3081 & 0,7056 & $0,0075^{* *}$ & 0,2038 & 0,1134 \\
H x D & 0,6558 & 0,9865 & 0,9128 & 0,8293 & 0,5574 & 0,5218 & 0,2289 \\
L x D & 0,8561 & 0,4906 & 0,9594 & 0,4212 & 0,5807 & 0,8352 & 0,9598 \\
H x L x D & 0,8959 & 0,2867 & 0,3823 & 0,8297 & 0,8012 & 0,8077 & 0,5138 \\
\hline D.M.S (5\%) & & & & & & & \\
Híbrido (H) & 1,47 & 0,19 & 0,82 & 0,20 & 0,09 & 0,16 & 2,45 \\
Lotes (L) & 1,47 & 0,19 & 0,82 & 0,20 & 0,09 & 0,16 & 2,45 \\
\hline C.V (\%) & 11,71 & 16,18 & 29,30 & 11,65 & 12,82 & 21,21 & 25,48 \\
\hline
\end{tabular}

*, ** Significativo à $5 \%$ e $1 \%$ respectivamente pelo teste $\mathrm{F}$, n.s não significativo. Médias seguidas de mesma letra não diferem à $5 \%$ pelo teste de Tukey. ${ }^{1} \mathrm{Y}=0,79 \mathrm{X}+2,47 \mathrm{R}^{2}=85,54 * *$

Verificou-se que não houve diferença significativa e que os dados não se ajustaram às equações testadas para os teores foliares de potássio e cálcio (Tabela 3).

Cultura Agronômica, Ilha Solteira, v.24, n.3, p.289-308, 2015 
O magnésio é absorvido pelas plantas em menores quantidades do que o $\mathrm{Ca}^{2+} \mathrm{e} \mathrm{K}^{+}$, com sua concentração não ultrapassando $0,5 \%$ da matéria seca dos tecidos (MARSCHNER, 1995). Com relação ao teor foliar de magnésio, observou-se que houve diferença significativa entre os híbridos, sendo que o híbrido A apresentou maiores teores de magnésio quando comparado com o híbrido B e C. Os lotes de milho-doce apresentaram diferença significativa, sendo os lotes de médio e baixo vigor os que apresentaram maiores concentrações de magnésio em relação ao lote de maior vigor. Em relação às doses de zinco não houve ajuste às funções testadas.

Tabela 4. Desdobramento da interação significativa entre Híbridos x Lotes, para os dados de teor de fósforo $(\mathrm{P})$.

\begin{tabular}{cccc}
\hline & \multicolumn{3}{c}{ Híbridos } \\
\cline { 2 - 4 } Lotes & $\mathrm{A}$ & $\mathrm{B}$ & $\mathrm{C}$ \\
\hline Alto & 3,39 a A & $2,80 \mathrm{~b} \mathrm{~A}$ & $2,54 \mathrm{~b} \mathrm{~B}$ \\
Médio & 3,26 a A & $3,02 \mathrm{a} \mathrm{A}$ & $3,22 \mathrm{a} \mathrm{A}$ \\
Baixo & 3,17 a A & $3,05 \mathrm{ab} \mathrm{A}$ & $2,72 \mathrm{~b} \mathrm{~B}$ \\
\hline DMS (5\%) & \multicolumn{2}{c}{ Híbridos dentro dos lotes } & 0,33 \\
& \multicolumn{2}{c}{ Lotes dentro dos híbridos } & 0,33 \\
\hline
\end{tabular}

a, b, c... (linha) - em cada híbrido, médias de lotes seguidas de mesma letra minúscula, não diferem pelo teste de Tukey (P > 0,05); A, B, C... (coluna) - em cada lote, médias de híbridos seguidas de mesma letra maiúscula, não diferem pelo teste de Tukey $(\mathrm{P}>0,05)$.

No desdobramento da interação significativa entre híbridos e lotes para teores foliares de magnésio (Tabela 5) observou-se que os híbridos A e B não apresentaram diferença significativa entre os lotes, já o híbrido $\mathrm{C}$ apresentou melhores resultados para os lotes de médio e baixo vigor. Para os lotes, observou-se que os lotes de alto, médio e baixo vigor apresentaram melhores resultados para o híbrido A quando comparado aos híbrido B e C.

Tabela 5. Desdobramento da interação significativa entre Híbridos x Lotes, para os dados de teor de magnésio $(\mathrm{Mg})$.

\begin{tabular}{cccc}
\hline & \multicolumn{3}{c}{ Híbridos } \\
\cline { 2 - 4 } Lotes & $\mathrm{A}$ & $\mathrm{B}$ & $\mathrm{C}$ \\
\hline Alto & $2,10 \mathrm{a} \mathrm{A}$ & $1,79 \mathrm{~b} \mathrm{~A}$ & $1,41 \mathrm{c} \mathrm{B}$ \\
Médio & $2,03 \mathrm{a} \mathrm{A}$ & $1,86 \mathrm{~b} \mathrm{~A}$ & $1,69 \mathrm{c} \mathrm{A}$ \\
Baixo & $2,05 \mathrm{a} \mathrm{A}$ & $1,82 \mathrm{~b} \mathrm{~A}$ & $1,60 \mathrm{c} \mathrm{A}$ \\
\hline DMS (5\%) & Híbridos dentro dos lotes & 0,15 \\
& Lotes dentro dos híbridos & 0,15 \\
\hline
\end{tabular}

a, b, c... (linha) - em cada híbrido, médias de lotes seguidas de mesma letra minúscula, não diferem pelo teste de Tukey (P > 0,05); A, B, C... (coluna) - em cada lote, médias de híbridos seguidas de mesma letra maiúscula, não diferem pelo teste de Tukey $(\mathrm{P}>0,05)$.

O teor de enxofre nas folhas (Tabela 3) apresentou diferença significativa entre os híbridos, sendo que o híbrido A apresentou concentrações superiores aos demais híbridos. Os lotes referentes ao vigor de sementes não apresentaram diferença significativa. Não houve ajuste de regressões para as doses de zinco.

Com relação aos teores foliares do zinco (Tabela 3) verifica-se que não foram 
observadas diferenças significativas entre híbridos e lotes. Para as doses de zinco os dados se ajustaram a uma função linear positiva, indicando que os teores foliares aumentaram com o aumento da dose aplicada. No entanto observa-se que todos os valores se encontram dentro da faixa considerada adequada para a cultura (CANTARELLA et al., 1997). Deste modo acredita-se que o zinco contido no solo, em função do baixo $\mathrm{pH}$, tenha ficado disponível para a absorção pelas plantas, e com isto foram supridas suficientemente, não ocorrendo assim deficiência do nutriente.

Tabela 6. Número de fileiras de grãos por espiga, número de grãos por fileira, diâmetro e comprimento da espiga de milho-doce cultivado em Selvíria- MS, safra 2011/2012.

\begin{tabular}{|c|c|c|c|c|c|c|}
\hline & & $\begin{array}{l}\text { Número de } \\
\text { fileiras de } \\
\text { grãos por } \\
\text { espiga }\end{array}$ & $\begin{array}{l}\text { Número de } \\
\text { grãos por } \\
\text { fileira }\end{array}$ & $\begin{array}{l}\text { Número de } \\
\text { grãos por } \\
\text { espiga }\end{array}$ & $\begin{array}{c}\text { Diâmetro } \\
\text { de espiga } \\
(\mathbf{m m})\end{array}$ & $\begin{array}{c}\text { Comprimento } \\
\text { de espiga } \\
\text { (cm) }\end{array}$ \\
\hline \multirow{3}{*}{ Híbridos } & A & $15,6 \mathrm{a}$ & $36,8 \mathrm{a}$ & $575,2 \mathrm{a}$ & $39,7 \mathrm{~b}$ & $17,8 \mathrm{ab}$ \\
\hline & B & $14,6 \mathrm{c}$ & $36,8 \mathrm{a}$ & $538,2 \mathrm{~b}$ & $43,2 \mathrm{a}$ & $17,5 \mathrm{~b}$ \\
\hline & $\mathrm{C}$ & $15,0 \mathrm{~b}$ & $36,6 \mathrm{a}$ & $551,4 \mathrm{~b}$ & $44,0 \mathrm{a}$ & $17,9 \mathrm{a}$ \\
\hline \multirow{3}{*}{ Lotes } & Alto & $15,0 \mathrm{a}$ & $37,4 \mathrm{a}$ & $547,4 \mathrm{a}$ & $42,0 \mathrm{a}$ & $17,6 \mathrm{a}$ \\
\hline & Médio & $15,0 \mathrm{a}$ & $37,2 \mathrm{a}$ & $560,0 \mathrm{a}$ & $42,8 \mathrm{a}$ & $17,9 \mathrm{a}$ \\
\hline & Baixo & $15,2 \mathrm{a}$ & $36,6 \mathrm{~b}$ & $557,4 \mathrm{a}$ & $42,1 \mathrm{a}$ & $17,7 \mathrm{a}$ \\
\hline \multirow{6}{*}{$\begin{array}{l}\text { Doses de } \\
\text { Zinco } \\
\left(\operatorname{kg~ha}^{-1}\right)\end{array}$} & 0 & 15,3 & 37,1 & 570,9 & 42,4 & 17,9 \\
\hline & 2 & 15,1 & 36,3 & 551,9 & 42,1 & 17,9 \\
\hline & 4 & 14,8 & 36,8 & 546,5 & 42,3 & 17,4 \\
\hline & 6 & 14,8 & 36,8 & 549,1 & 42,2 & 17,6 \\
\hline & 8 & 15,2 & 36,7 & 561,8 & 42,5 & 18,1 \\
\hline & 10 & 15,0 & 36,6 & 549,4 & 42,3 & 17,6 \\
\hline
\end{tabular}

\begin{tabular}{clllll}
\hline Teste F & & & & \\
Híbrido (H) & $0,0001^{* *}$ & 0,7179 & $0,0001^{* *}$ & $0,0001^{* *}$ & $0,0132^{* *}$ \\
Lotes (L) & 0,3959 & $0,0207^{*}$ & 0,2223 & $0,0470^{*}$ & 0,1070 \\
Doses (D) & 0,1137 & 0,6638 & 0,1832 & 0,9824 & 0,0506 \\
H x L & 0,7537 & 0,0591 & 0,4278 & $0,0255^{*}$ & 0,0572 \\
H x D & 0,0857 & 0,8722 & 0,1335 & 0,7529 & 0,7022 \\
L x D & 0,4651 & 0,4498 & 0,3348 & 0,9875 & 0,9411 \\
H x L x D & 0,8298 & 0,2340 & 0,8305 & 0,9574 & 0,6515 \\
\hline D.M.S (5\%) & & & & & \\
Híbridos (H) & 0,38 & 0,74 & 18,13 & 0,86 & 0,37 \\
Lotes (L) & 0,38 & 0,74 & 18,13 & 0,86 & 0,37 \\
\hline C.V (\%) & 6,54 & 5,17 & 8,28 & 5,20 & 5,35
\end{tabular}

*,** Significativo à $5 \%$ e $1 \%$ respectivamente pelo teste $\mathrm{F}, \mathrm{n} . \mathrm{s}$ não significativo. Médias seguidas de mesma letra não diferem à $5 \%$ pelo teste de Tukey.

Em relação às diferenças entre híbridos para o número de fileiras de grãos por espiga (Tabela 6) verificou-se que o híbrido A apresentou resultados superiores aos demais 
híbridos, porém não foram observadas diferenças entre os lotes de sementes. Também não houve ajustes significativos de regressões em relação às doses de zinco.

Quanto ao número de grãos por fileira (Tabela 6) observou-se que não houve diferença significativa entre os híbridos. Contudo pode ser constatado que o lote de maior vigor apresentou melhores resultados para o número de grãos por fileira, enquanto o lote de baixo vigor foi o de pior desempenho. Por outro lado, o lote classificado como de vigor intermediário, apresentou desempenho semelhante ao do lote de maior vigor.

Tabela 7. Número de espigas totais, número de espigas comerciais e índice de produção comercial no milho doce cultivado em Selvíria-MS, safra 2011/2012.

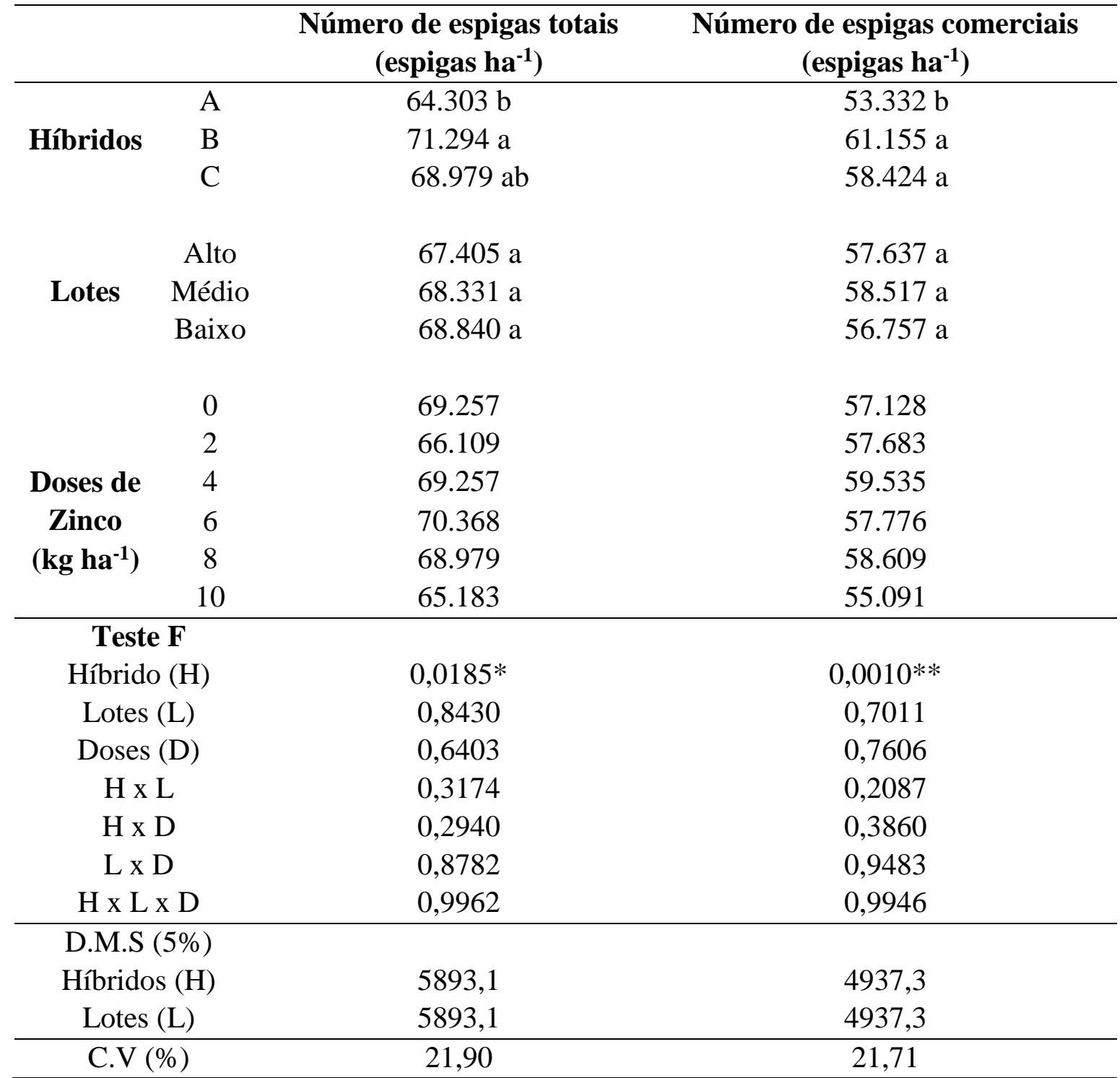

*, ** Significativo à $5 \%$ e $1 \%$ respectivamente pelo teste $\mathrm{F}, \mathrm{n} . \mathrm{s}$ não significativo. Médias seguidas de mesma letra não diferem à $5 \%$ pelo teste de Tukey.

Em relação às doses de zinco não houve ajuste de regressões. Para a variável número de grãos por espiga (Tabela 6) observou-se que houve diferença significativa entre os híbridos, com o híbrido A apresentando melhores resultados quando comparado com os híbridos B e C, apresentando maior produção de grãos por espiga. Para os lotes, a análise

Cultura Agronômica, Ilha Solteira, v.24, n.3, p.289-308, 2015 
estatística não indicou diferença significativa. Quando foram comparadas as doses de zinco pode-se observar que não houve efeito do nutriente para essa variável.

Para produtividade total de espigas com palha e despalhadas (Tabela 8) verificou-se diferença significativa entre os três híbridos de milho-doce, com B e C superiores significativamente ao híbrido A. Observou-se que não houve diferença significativa para os lotes de sementes e ajuste de regressões para as doses de zinco.

Tabela 8. Produtividade total de espigas com palha, produtividade total de espigas sem palha e produtividade comercial de espigas sem palha no milho doce cultivado em SelvíriaMS, safra 2011/2012.

\begin{tabular}{|c|c|c|c|c|c|}
\hline & & $\begin{array}{l}\text { Produtividade } \\
\text { total de espigas } \\
\text { com Palha } \\
\left(\mathrm{kg} \mathrm{ha}^{-1}\right)\end{array}$ & $\begin{array}{c}\text { Produtividade } \\
\text { total de espigas } \\
\text { despalhadas } \\
\left(\mathrm{kg} \mathrm{ha}^{-1}\right)\end{array}$ & $\begin{array}{c}\text { Produtividade } \\
\text { comercial de } \\
\text { espigas despalhadas } \\
\left(\mathrm{kg} \mathrm{ha}^{-1}\right)\end{array}$ & $\begin{array}{c}\text { Índice de } \\
\text { produtividade } \\
\text { comercial }\end{array}$ \\
\hline \multirow{3}{*}{ Híbridos } & A & $10.151 \mathrm{~b}$ & $6.823 \mathrm{~b}$ & $5.645 \mathrm{~b}$ & $83,1 \mathrm{a}$ \\
\hline & $\mathrm{B}$ & $13.030 \mathrm{a}$ & $9.239 \mathrm{a}$ & $7.929 \mathrm{a}$ & $86,4 \mathrm{a}$ \\
\hline & $\mathrm{C}$ & $13.419 \mathrm{a}$ & $9.546 \mathrm{a}$ & $8.102 \mathrm{a}$ & 84,9 a \\
\hline \multirow{3}{*}{ Lotes } & Alto & $11.774 \mathrm{a}$ & $6.011 \mathrm{a}$ & $5.824 \mathrm{a}$ & $85,7 \mathrm{a}$ \\
\hline & Médio & $12.768 \mathrm{a}$ & $6.065 \mathrm{a}$ & $5.598 \mathrm{a}$ & $85,1 \mathrm{a}$ \\
\hline & Baixo & $12.058 \mathrm{a}$ & $6.716 \mathrm{a}$ & $5.014 \mathrm{~b}$ & 82,9 a \\
\hline \multirow{6}{*}{$\begin{array}{c}\text { Doses de } \\
\text { Zinco } \\
\left(\mathrm{kg} \mathrm{ha}^{-1}\right)\end{array}$} & 0 & 12.551 & 6.429 & 5.462 & 82,5 \\
\hline & 2 & 11.997 & 6.017 & 5.177 & 86,8 \\
\hline & 4 & 12.331 & 6.333 & 5.465 & 86,0 \\
\hline & 6 & 12.320 & 6.291 & 5.313 & 82,8 \\
\hline & 8 & 12.089 & 6.262 & 5.299 & 86,0 \\
\hline & 10 & 11.912 & 6.250 & 5.356 & 84,7 \\
\hline
\end{tabular}

\begin{tabular}{ccccc}
\hline Teste F & & & & \\
Híbrido (H) & $0,0001^{* *}$ & $0,0001^{* *}$ & $0,0001^{* *}$ & 0,0945 \\
Lotes (L) & 0,1781 & 0,1678 & $0,0452^{*}$ & 0,0840 \\
Doses (D) & 0,9645 & 0,9089 & 0,9487 & 0,2015 \\
H x L & 0,3169 & 0,4335 & 0,2655 & 0,5851 \\
H x D & 0,7812 & 0,6978 & 0,7598 & 0,3267 \\
L x D & 0,8998 & 0,8891 & 0,9738 & 0,8281 \\
H x L x D & 0,9687 & 0,9986 & 0,9995 & 0,8607 \\
\hline D.M.S (5\%) & & & & 3,52 \\
Híbridos (H) & 1297,9 & 944,7 & 801,46 & 3,52 \\
Lotes (L) & 1297,9 & 944,7 & 801,46 & 10,53 \\
\hline C.V (\%) & 26,96 & 28,04 & 28,11 & \\
\hline
\end{tabular}

*, ** Significativo à $5 \%$ e $1 \%$ respectivamente pelo teste $\mathrm{F}, \mathrm{n} . \mathrm{s}$ não significativo. Médias seguidas de mesma letra não diferem à $5 \%$ pelo teste de Tukey.

Nos resultados relativos à produtividade comercial de espigas despalhadas (Tabela 8) observa-se que houve diferença significativa entre os híbridos, sendo os híbridos $\mathrm{B}$ e $\mathrm{C}$ 
superiores ao híbrido A. Para os lotes de sementes, diferentes quanto ao nível e vigor, observou-se que houve maior produtividade comercial de milho-doce de plantas originadas dos lotes mais vigorosos (alto e médio vigor) com $5.824 \mathrm{~kg} \mathrm{ha}^{-1}$ e $5.598 \mathrm{~kg} \mathrm{ha}^{-1}$ respectivamente, em relação ao lote de menor vigor com $5.014 \mathrm{~kg} \mathrm{ha}^{-1}$. Assim ficou evidenciado que em termos qualitativos, pode ocorrer efeito do nível de vigor das sementes sobre a qualidade do material colhido.

Conforme Marcos Filho (2005), o efeito do vigor das sementes sobre a produtividade das plantas é muito variável e as conclusões da pesquisa muito diversificadas. De acordo com Tekrony e Egli (1991), em espécies em que o produto é retirado do campo no início da fase reprodutiva (ervilha, milho-doce, tomate), a semeadura é efetuada para obtenção de populações mais elevadas por área, em relação às utilizadas para as espécies colhidas durante a fase vegetativa. Nesses casos, e também quando o produto é colhido ao atingir a maturidade (milho, soja, feijão, trigo e outros), não tem sido registrada, de maneira consistente, a influência do vigor da semente sobre a produção final, na ausência de diferenças no estande. Assim este indício de efeito do nível de vigor das sementes sobre a produção comercial necessita de mais estudos para melhor elucidar o assunto.

Embora haja citações da importância do zinco para a cultura do milho, as condições ambientais (solo e clima) são de fundamental importância para que possam ser efetivados os processos de absorção e transporte dos nutrientes. Como neste experimento o solo apresentava um $\mathrm{pH}(4,9)$ relativamente baixo, é possível que embora o zinco se apresentasse em um nível baixo no solo $(0,40 \mathrm{mg} / \mathrm{dm} 3)$, a quantidade disponibilizada para as plantas tenha sido suficiente para supri-las, o que pode ser visto na análise foliar das plantas de milho-doce, todas as doses testadas, mesmo a testemunha apresentaram teores adequados de zinco para a cultura do milho de acordo com Cantarella et al. (1997).

O índice de produtividade comercial (Tabela 8) não apresentou diferença significativa para híbridos e lotes de milho-doce, e não houve resposta para as doses de zinco aplicadas.

\section{CONCLUSÃO}

Os três híbridos de milho-doce se apresentaram aptos para serem cultivados na região de Selvíria-MS. Há diferença de comportamento entre os híbridos em relação à produção comercial de espigas, sendo os híbridos B e C superiores ao híbrido A.

Sementes de lotes de alto vigor proporcionaram maior número de grãos por fileira e maior produtividade comercial de espigas de milho-doce.

A adubação com zinco via solo até a dose $10 \mathrm{~kg} \mathrm{ha}^{-1}$ não afetou as características agronômicas e a produtividade dos híbridos de milho-doce testados.

\section{AGRADECIMENTOS}

A Fundação de Amparo à Pesquisa do Estado de São Paulo (FAPESP) pela concessão de suporte financeiro à pesquisa.

Cultura Agronômica, Ilha Solteira, v.24, n.3, p.289-308, 2015 


\section{REFERÊNCIAS BIBLIOGRÁFICAS}

ARAGÃO, C. A. Avaliação de híbridos simples braquíticos de milho super doce (Zea mays $L$.) portadores do gene shrunken-2 (sh2sh2) utilizando o esquema dialélico parcial. 2002, 101 f. Tese (Doutorado em Agronomia) - Faculdade de Ciências Agronômicas, Universidade Estadual Paulista, Botucatu, 2002.

BARBIERI, V. H. B.; LUZ, J. M. Q.; BRITO, C. H.; DUARTE, J. M.; GOMES, L. S.; SANTANA, D. G. Produtividade e rendimento industrial de híbridos de milho doce em função de espaçamento e populações de plantas. Horticultura Brasileira, Brasília, v. 23, n. 3, p.826-830, 2005.

BORIN, A. L. D. C. Extração, absorção e acúmulo de nutrientes no milho doce cultivado em condições de campo. 2005. 97 f. Tese (Mestrado em Agronomia) Universidade Federal de Viçosa, Uberlândia, 2005.

BRASIL. Ministério da Agricultura, Pecuária e Abastecimento. Regras para análise de sementes. Brasília: MAPA/ACS, 2009. 399 p.

BRASIL. Ministério da Agricultura, Pecuária e Abastecimento. Instrução normativa n. 25, de 16 de dezembro de 2005. Padrões para produção e comercialização de sementes de milho-cultivares híbridas. Diário Oficial da União, sec.1, n.243, p.18, Brasília, DF, de 20

dez. 2005. Disponível em: < http://sistemasweb.agricultura.gov.br/sislegis/action/detalhaAto.do?method=consultarLegisl acaoFederal>. Acesso em: 21 set. 2012.

CANTARELlA, H.; RAIJ, B. Van.; CAMARGO, C. E. O. Cereais. In: RAIJ, B. Van.; CANTARELlA, H.; QUAGGIO, J. A. (Eds.). Recomendação de adubação e calagem para o Estado de São Paulo. 2. ed. Campinas: IAC, 1997. cap.13, p. 45-71. (Boletim técnico, 100)

CRUZ, J. C.; PEREIRA FILHO, I. A. Manejo e tratos culturais para o cultivo do milho verde. Sete Lagoas: Embrapa Milho e Sorgo, 2002. 64 p. (Circular Técnica, 16).

DEMATTÊ, J. L. I. Levantamento detalhado de solos do "Câmpus Experimental de Ilha Solteira". Piracicaba: Departamento de Solos, Geologia e Fertilidade - ESALQ/USP, 1980. 44 p.

EMPRESA BRASILEIRA DE PESQUISA AGROPECUÁRIA-EMBRAPA - EMBRAPA. Sistema brasileiro de classificação de solos. Rio de Janeiro: Centro Nacional de Pesquisa de Solo, 2006. 316 p. 
FAGIOLI, M. Relação entre condutividade elétrica e ou de sementes e a emergência de plântulas de milho em campo. 1997. 74 f. Dissertação (Mestrado em Produção e Tecnologia de Sementes) - Universidade Estadual Paulista, Jaboticabal.

FERREIRA, D. F. SISVAR Sistema de análise estatística para dados balanceados. Lavras: UFLA/DEX, 2000. (CD-ROM).

GAMA, E. E. G.; MORO, J. R.; MAGNAVACA, R.; VIANA, R. T.; NASPOLINI FILHO, V. Melhoramento do milho. Brasília: EMBRATER, p. 23-38, 1983.

HAMPTON, J. G.; TEKRONY, D. M. Condutivity test. In: HAMPTON, J. G.; TEKRONY, D. M. Handbook of vigour test methods. 3 .ed. Zürich: ISTA, 1995. p. 22-34.

HERNANDEZ, F. B. T.; LEMOS-FILHO, M. A.; BUZZETI, S. Software Hidrisa e o balanço hídrico de Ilha Solteira. Ilha Solteira: Faculdade de Engenharia de Ilha Solteira UNESP - área de Hidráulica e Irrigação, 1995. 45 p.

HÖFS, A. Vigor de sementes de arroz e desempenho da cultura. 2003. $44 \mathrm{f}$. Tese (Doutorado em Ciência e Tecnologia de Sementes) - Universidade Federal de Pelotas, Pelotas, 2003.

LOEFFLER, T. M.; TEKRONY, D. M.; EGLI, D. B. The bulk conductivity test as an indicator of soybean seed quality. Journal Seed Technology, Springfield, v. 12, n. 1, p.37$53,1988$.

KOLCHINSKI, E. M.; SCHUCH, L. O. B.; PESKE, S. T. Vigor de sementes e competição intra-específica em soja. Ciência Rural, Santa Maria, v. 35, n. 6, p.1248-1256, 2005.

MACHADO, R. F. Desempenho de aveia-branca (Avena sativa L.) em função do vigor de sementes e população de plantas. 2002. 46 f. Dissertação (Mestrado em Ciência e Tecnologia de Sementes) - Universidade Federal de Pelotas, Pelotas, 2002.

MARCOS FILHO, J. Fisiologia de sementes de plantas cultivadas. Piracicaba: FEALQ, 2005. $495 \mathrm{p}$.

MARCOS FILHO, J.; SILVA, W. R.; NOVEMBRE, A. C.; CHAMA, H. Estudo comparativo de métodos para a avaliação da qualidade fisiológica de sementes de soja, com ênfase ao teste de condutividade elétrica. Pesquisa Agropecuária Brasileira, Brasília, v. 25, n. 12, p.1805-15, 1990.

MARCOS FILHO, J. Teste de envelhecimento acelerado. In: VIEIRA, R. D.; CARVALHO, N. M. (Ed.). Teste de vigor em sementes. Jaboticabal: FUNEP, 1994. p.133-149.

Cultura Agronômica, Ilha Solteira, v.24, n.3, p.289-308, 2015 
MARSCHNER, H. Mineral nutrition of higher plants. London: Academic Press, 2 Ed., 1995. 889 p.

MASSEY, H. F.; LOEFEL, F. A. Variation of zinc content of grain from inbred lines of corn. Agronomy Journal, Madison, v. 58, n. 2, p.143-144, 1966.

OLIVEIRA JUNIOR, L. F. G.; DELIZA, R.; BRESSAN-SMITH, R.; PEREIRA, M. G.; CHIQUIERE, T. B. Seleção de genótipos de milho mais promissores para o consumo in natura. Ciência e Tecnologia de Alimentos, Campinas, v. 26, n. 1, p.159-165, 2006.

PARENTONI, S. N.; GAMA, E. E. G.; MAGNAVACA, R.; REIFSCHSNEIDER, F. J. B.; VILLAS BOAS, G. L. Milho doce. Informe Agropecuário, Belo Horizonte, v. 14, n. 165, p.17-22, 1990.

PEREIRA FILHO, I. A.; CRUZ, J. C. Cultivares de milho para o consumo verde. Sete Lagoas :Embrapa Milho e Sorgo, p.1-7, 2002. (Circular Técnica, 15.)

POWELL, A. A. Cell membranes and seed leachate conductivity in relation to the quality of seed for sowing. Journal of Seed Technology, Lincoln, v. 10, n. 2, p.81-100, 1986.

PRADO, R. M.; NATALE, W.; MOURO, M. C. Fontes de zinco aplicado via semente na nutrição e crescimento inicial do milho cv. Fort. Bioscience Journal, Uberlândia, v. 23, n. 2, p.16-24, 2007.

RAIJ, B. Van; CANTAREllA, H.; QUAGGIO, J. A.; FURLANI, A. M. C. Recomendação de adubação e calagem para o Estado de São Paulo. Campinas: Instituto Agronômico / Fundação IAC, 1997. 285 p. (Boletim técnico, 100)

RAIJ, B. Van; QUAGGIO, J.A. Métodos de análise de solo para fins de fertilidade. Campinas: Instituto Agronômico, 1983. 31 p. (Boletim Técnico, 81).

SÁ, M. E. Condutividade elétrica em sementes de tomate (Lycopersicon lycopersicum L.). Scientia Agricola, Piracicaba, v. 56, n. 1, p.1-9, 1999.

SANTOS, M. R. Qualidade fisiológica, sanidade e alterações bioquímicas em sementes de soja e suas relações com potencial de armazenamento e emergência no campo. 2004. 104 f. Tese (Doutorado em Fitotecnia) - Universidade Federal de Viçosa, Viçosa, 2004.

SCHUCH, L. O. B.; NEDEL, J. L.; ASSIS, F. N.; MAIA, M. S. Crescimento em laboratório de plântulas de aveia-preta (Avena strigosa Schreb.) em função do vigor das sementes. Revista Brasileira de Sementes, Brasília, v. 21, n. 1, p.229-234, 1999. 
SCHUCH, L.O.B.; LIN, S. S. Atraso na colheita sobre emergência no campo e desempenho de plantas de trigo. Pesquisa Agropecuária Brasileira, Brasília, v. 17, n. 11, p.1585- 1589, 1982.

STORK, L.; LOVATO, C. Milho doce. Ciência Rural, Santa Maria, v. 21, n. 2, p.283-292, 1991.

TEKRONY, D. M.; EGLI, D. B. Relationship of seed vigor to crop yield: a review. Crop Science, Madison, v. 31, n. 3, p.816-822, 1991.

VANZOLINI, S.; CARVALHO, N. M. Efeito do vigor de sementes de soja sobre o seu desempenho em campo. Revista Brasileira de Sementes, Brasília, v. 24, n. 1, p.33-41, 2002.

VIEIRA, R. D.; TEKRONY, D. M.; EGLI, D. B.; RUCKER, M. Electrical conductivity of soybean seeds after storage in several environments. Seed Science and Technology, Zürich, v. 29, n. 3, p.599-608, 2001.

VIEIRA, R. D.; MINOHARA, L.; PANOBIANCO, M.; BERGAMASCHI, M. C. M.; MAURO, A.O. Comportamento de cultivares de soja quanto à qualidade fisiológica de sementes. Pesquisa Agropecuária Brasileira, Brasília, v. 33, n. 2, p.123-130, 1998.

VIEIRA. R. D. Teste de condutividade elétrica. In: VIEIRA, R. D.; CARVALHO, N. M. (Ed.). Testes de vigor em sementes. Jaboticabal: FUNEP, 1994. p.103-132.

WATERS JÚNIOR, L.; BLANCHETTE, B. Prediction of sweet corn field emergence by conductivity and cold tests. Journal of American Society Horticultural Science, Alexandria, v. 108, n. 5, p.778-781, 1983.

Cultura Agronômica, Ilha Solteira, v.24, n.3, p.289-308, 2015 
